Personality and individual differences, in press

\title{
ARE ATTACHMENT STYLES DIFFERENTIALLY RELATED TO INTERPERSONAL PERFECTIONISM AND BINGE EATING SYMPTOMS?
}

Liesbet Boone*

Ghent University, Belgium

Department of Developmental, Social, and Personality Psychology

* Correspondence concerning this article can be addressed to Liesbet Boone, Faculty of Psychology, Department of Developmental, Social, and Personality Psychology, Henri Dunantlaan, 2 B-9000 Ghent, Belgium. E-mail: Liesbet.Boone@UGent.be, Tel: +32 (0)9 26464 86. Fax: +32 (0)9 2646499 .

Note: The first author is research assistant at the Special Research Funds (BOF). 


\begin{abstract}
In the current study we aimed to examine the association between attachment styles towards father and mother, perfectionistic self-promotion (PSP), socially prescribed perfectionism (SPP), and binge eating symptoms in a sample of 328 late adolescents (mean age 17.1 years). It was examined whether anxiously and avoidantly attached adolescents would differentially cope with their insecure feelings. It was hypothesized that anxiously attached adolescents would, through hyperactivating strategies, be hypersensitive to the expectations of others. Avoidantly attached adolescents were hypothesized to present a perfect image of the self, because of their deactivating emotion regulation. Furthermore, the mediating role of perfectionism in the relation between attachment representations and binge eating symptoms was examined. Results showed that anxious attachment was significantly positively associated with PSP, SPP, and binge eating. Avoidant attachment towards mother was only positively associated with SPP, whereas avoidant attachment towards father was positively associated with PSP and binge eating. PSP fully mediated the relation between avoidant attachment towards father and binge eating. Interestingly, the current findings showed the importance of examining attachment representations towards both parents.
\end{abstract}

Key Words: Attachment, Adolescence, Interpersonal Perfectionism, Binge Eating Symptoms 


\section{Introduction}

Bowlby's attachment theory (Bowlby, 1982/1969) is one of the most prominent and useful frameworks to conceptualize the relationship between parents and children and to understand the process of affect regulation (Mikulincer, Shaver, \& Pereg, 2003). Attachment theory states that, on the basis of early interactions with attachment figures, children develop secure or insecure attachment representations. According to the model of Mikulincer and Shaver (2007), attachment styles are conceptualized as regions in a twodimensional space. These dimensions are referred to as attachment anxiety and attachment avoidance. Individuals scoring high on one of these dimensions are said to be insecurely attached. Individuals scoring low on both attachment anxiety and avoidance are called securely attached individuals. Individuals scoring high on anxious attachment are preoccupied with fear of interpersonal rejection or abandonment and use more hyperactivating strategies, whereas individuals scoring high on avoidance attachment are more preoccupied with fear of interpersonal closeness or independence and make more use of deactivating strategies to regulate stress and emotions (Mikulincer, et al., 2003). Hyperactivating strategies are characterized by constant vigilance, concern, and effort to reestablish proximity, involvement and care from the attachment figure. These strategies typically involve clinging and dependent behavior, and feelings of helplessness and incompetence in regulating one's affect. Deactivating strategies are characterized by the attempt to regulate distress alone, in which closeness, intimacy and dependence on others is totally denied. By striving for self-reliance and independence, avoidantly attached individuals tried to avoid frustration and distress when the attachment figure was not available. Although both hyperactivating and deactivating strategies may have a function in coping with emotional stress, they are maladaptive secondary emotion regulation strategies 
(Mikulincer, et al., 2003) and have been found to be associated with psychopathology (e.g., Brenning, Soenens, Braet, \& Bosmans, 2012).

Attachment insecurity has been linked to both perfectionism (Rice \& Mirzadeh, 2000) and eating disorder (ED) pathology (Ward, Ramsay, \& Treasure, 2000). Research has shown that adolescents who are avoidantly and anxiously attached were more self-critical and had higher levels of evaluative concerns of perfectionism (Thompson \& Zuroff, 1999; Wei, Heppner, Russell, \& Young, 2006). With regard to ED symptoms, several studies found that insecure attachment is more prevalent in ED populations than in non-clinical samples (Zachrisson \& Skarderud, 2010). Cole-Detke and Kobak (1996) found that women with deactivating strategies were more prone to report elevated levels of ED symptoms. In a recent study among adolescents, it was found that insecure attachment was positively associated with binge symptoms in female adolescents (Pace, Cacioppo, \& Schimmenti, 2012).

Binge eating symptoms (uncontrollable eating of a large amount of food in a short period of time) are highly prevalent in adolescent boys and girls (Abebe, Lien, Torgersen, \& von Soest, 2012). Binge eating is found to occur in response to excessive dieting (Fairburn, Cooper, \& Shafran, 2003) or to act as a compensatory mechanism to cope with or to escape from negative feelings (Spoor, Bekker, Van Strien, \& van Heck, 2007). Consistent with the latter theory, binge eating serves the function of maladaptive emotion regulation, such as avoidant coping. Indeed, it has been found that eating disordered patients typically have poor emotion recognition and regulation capacities (Harrison, Sullivan, Tchanturia, \& Treasure, 2009).

An extensive body of research has shown that avoidant attachment is strongly related with a self-critical personality style and depression (Blatt, 2004). Self-critical 
individuals are preoccupied with themes such as self-definition and self-worth, and tend to focus solely on achievement and control, at the expense of interpersonal relationships (Blatt, 2004). However, less research investigated the role of more interpersonal aspects of perfectionism, such as perfectionistic self-promotion and socially prescribed perfectionism.

On the basis of Mikulincer and Shaver's model of emotion regulation (Shaver \& Mikulincer, 2002), it could be hypothesized that avoidantly and anxiously attached individuals will differentially cope with distress. It could be expected that anxiously attached individuals' hyperactivating strategies will drive them to try to attain to the perceived standards from others (socially prescribed perfectionism) in order to gain or maintain others' love and approval. Avoidant people's deactivating strategies are hypothesized to incline them towards the setting of high standards for themselves (perfectionistic self-promotion) in order to appear perfect and independent, and to defensively maintain a sense of superiority. Indeed, perfectionistic self-presentation has been described as a defensive coping strategy that is used to deal with a threatened view of the self, and ineffectively tries to build up or maintain a positive view of the self (Hewitt, et al., 2003).

\subsection{The present study}

In this study, our aims were two-fold. First, in a non-clinical sample of adolescent males and females we aimed to examine whether attachment styles (avoidant, anxious, and secure attachment) were differentially related to perfectionistic self-promotion (PSP), socially prescribed perfectionism (SPP), and binge eating symptoms. On the basis of Mikulincer and Shaver's model of emotion regulation, we expected that anxious attachment will be uniquely associated with SPP, whereas avoidant attachment will be uniquely associated with PSP. Secure attachment is expected to be negatively associated with both perfectionism components. Insecure attachment is hypothesized to be positively related to 
binge eating, whereas the inverse relation for secure attachment was expected (Ward, et al., 2000). Second, a mediating model was tested in which it was examined whether SPP and PSP can explain why respectively anxious and avoidant attachment are related to binge eating symptoms. Moreover, since the majority of research on attachment only focusses on attachment towards the mother and previous research showed that also fathers play an important role in attachment and binge eating (Pace, et al., 2012), attachment styles were assessed with regard to both parents.

\section{Method}

\subsection{Participants and procedure}

A total of 328 late-adolescent females (57\%) and males (43\%) from two high schools in Belgium participated in the study, with a mean age of 17.1 years $(S D=1.13$, range $=14-$ 20). Males and females did not differ in age $(t(325)=-1.68, p>.05)$, but males tended to have a higher adjusted BMI compared to females ( $t(313)=-5.43, p<.001)$. All participants were Caucasian, following the academic track, and came from middle-class backgrounds. Of the participants, $78 \%$ came from intact, two parent families, $20 \%$ had divorced parents, $2 \%$ came from a family in which one of the parents had died. We obtained passive informed consents from parents and active written assent from the adolescents. Adolescents got the opportunity to withhold participation at any moment during the assessment. The response rate to participate in the study was $82 \%$.

\subsection{Instruments}

2.2.1. Attachment. Insecure attachment styles were measured using the Experiences in Close Relationships Scale (ECR-R; Fraley, Waller, \& Brennan, 2000). The ECR-R consists of 36-items (rated on a 7-point Likert scale) and measures attachment anxiety and avoidance. 
The ECR-R is a generic measure of relationships, allowing one to use its items to ask for different types of relationships. In this study, attachment representations towards mother and father were asked separately, and measures were not counterbalanced. The ECR-R has been found to show good psychometric properties (Fraley, et al., 2000). Secure attachment towards mother and father was measured using the subscale trust of the People in my Life (PIML; Cook, Greenberg, \& Kusche, 1995). This subscale contains 10-items, with scores ranging from 1 to 4 . The PIML is designed to measure children's representations of their relationship with parents, peers, and teachers and has good psychometric properties (Murray \& Greenberg, 2006).

2.2.2. Perfectionism. From the Perfectionistic Self-presentation Scale (PSPS; Hewitt, et al., 2003), the 10-item subscale Perfectionistic self-promotion (PSP) was used to measure the attempt to which a person demonstrates one's supposed perfection to others by actively and unrealistically presenting one's positive abilities, accomplishments, and successes. This scale is rated on a 7-points Likert scale and has been proven to be a valid and reliable measure (Hewitt, et al., 2003). Socially prescribed perfectionism (SPP) was measured using the multidimensional perfectionism of Hewitt and Flett (MPS-H\&F; Hewitt \& Flett, 1991). The subscale SPP is a subscale of the MPS, assessing the extent to which people believe that others have unrealistic standards for them, evaluate them stringently, and exert pressure on them to perform perfectly. This subscale contains 15 items, scored on a 7-points Likert scale, and has been shown to have good psychometric properties (Hewitt \& Flett, 1991).

2.2.3. Binge eating symptoms. Binge eating symptoms were measured using the bulimia scale of the eating disorder inventory II (Garner, 1991). This subscale contains 8 items, assessing binge eating and purging. Because only one item measures purging 
behavior, this item was deleted, resulting in a 7-point scale measuring binge eating symptoms (see also Boone, et al., 2012).

\subsection{Analyses}

First, to test for differences between gender among the study variables, a single ANOVA was performed with gender as independent variable and the study variables as dependent variables. Second, to investigate the associations between the background variables and the study variables, zero-order correlations were calculated. Third, to examine the mediating role of perfectionism components between attachment styles and binge eating, we followed the four step procedure of Kenny, Kashy and Bolger (1998), controlling for age, gender, adjusted BMI, and family status. According to the four step procedure, conditions in all paths should be met to show mediation. Step 1 requires a significant path from the independent variable (attachment) to the dependent variable (binge eating). Step 2 involves a significant path from the independent variable to the mediating variable (PSP and SPP). Step 3 requires finding a significant path from the mediating to the dependent variable, controlling for the independent variable. Finally, step 4, mediation is shown when the initial significant effect of the independent variable on the dependent variable is reduced to non-significance after controlling for the mediator.

\section{Results}

\subsection{Preliminary Results}

Single ANOVA's revealed that gender differences were significant for attachment avoidance towards mother $(F(1,325)=17.47, p<.001)$, attachment avoidance $(F(1,317)=$ 4.99, $p<.05)$ and secure attachment $(F(1,318)=5.41, p<.05)$ towards father, and binge eating symptoms $(F(1,324)=10.92, p<.01)$. Boys reported more avoidant attachment 
towards mother and more secure attachment towards father compared to girls, whereas girls reported more avoidant attachment towards father and more binge eating symptoms compared to boys. Furthermore, we have looked at whether gender moderated the effects of insecure and secure attachment in the prediction of PSPS, PS, and binge eating. However, none of these interaction terms were significant (above and beyond the main effects of attachment and gender), suggesting that the effects of attachment to the mother and father were not stronger for girls and boys respectively (i.e., same-sex linkage hypothesis; Cassidy, 1990). Family status had significant effects on trust towards mother $(F(2,320)=4.92, p<.01)$ and father $(F(2,313)=3.94, p<.05)$, avoidance $(F(2,312)=8.91, p<.001)$ and anxiety $(F(1,314)=7.47, p<.01)$ towards father. Adolescents from an intact family reported most trust, and least avoidant and anxious attachment, whereas adolescents for whom one of the parents died reported the least trust, and the most avoidant and anxious attachment towards the father. Zero-order correlations between the attachment styles towards father and mother, perfectionism components and binge eating are shown in Table 1. Anxious attachment towards mother and father was significantly positively associated with PSP, SPP, and binge eating. Avoidant attachment towards mother was only positively associated with SPP, whereas avoidant attachment towards father was positively associated with PSP and binge eating ${ }^{1}$. Secure attachment towards both mother and father was negatively associated with both perfectionism components and binge eating.

\subsection{Mediating Role of Perfectionistic Self-promotion in the Relation Between Attachment} Style and Binge eating symptoms

As can be seen in Table 2, controlling for background variables, in the first three steps, path coefficients for attachment anxiety towards mother and father, avoidant 
attachment towards mother, and secure attachment towards mother and father were significant. When entering SPP at step 4, the path coefficients of the attachment representations and binge eating were reduced significantly. For avoidant attachment towards mother, the coefficient became non-significant. Sobel tests (1982) were all significant and bias-corrected and accelerated (BCa) confidence intervals (95\%) did not contain zero (Preacher \& Hayes, 2004), showing that the indirect effects of these attachment representations to binge eating were significant. Although SPP fully mediated the relation between attachment avoidance towards mother and binge eating, this indirect effect was rather small.

\subsection{Mediating Role of Socially Prescribed Perfectionism in the Relation Between Attachment Style and Binge eating symptoms}

As can be seen in Table 2, controlling for background variables, in the first three steps, path coefficients for attachment anxiety towards mother and father, avoidant attachment towards father and secure attachment towards mother and father were significant. When entering PSP at step 4, the path coefficient of the avoidant attachment and binge eating was reduced to non-significance. For the other four paths, the path coefficients of the attachment representations were reduced significantly. Sobel tests were all significant and bias-corrected and accelerated (BCa) confidence intervals (95\%) did not contain zero, showing that the indirect effects of these attachment representations to binge eating were significant. Only the indirect effect of secure attachment towards mother on binge eating was rather small.

\section{Discussion}


Because previous studies never looked at the association between interpersonal perfectionism and binge eating (e.g., Hewitt, Flett, \& Ediger, 1995) in relation to attachment representations, this was the aim of the current study.

As predicted, we found evidence for SPP to be strongly associated with anxious attachment towards both parents. There was a less strong, but significant association between SPP and avoidant attachment towards the mother. PSP was only associated with attachment avoidance towards father, and not to the mother. Contrary to our hypothesis, but in line with a recent study of Chen and colleagues (2012) PSP was associated with anxious attachment towards both father and mother. Our correlational findings did thus not provide overall evidence for the differential association between anxious attachment and avoidant attachment with SPP and PSP respectively.

First, it seemed that anxious attachment was more strongly related to both perfectionism components compared to avoidant attachment. These findings suggest that anxiously attached adolescents tend to have a stronger need to appear perfect and to attain to others' expectancies compared to avoidantly attached adolescents. Given that anxiously attached individuals are typically characterized by a strong desire for closeness and use clinging and proximity seeking behaviors to deal with insecurity and distress, it is somewhat surprising that it was also strongly related to PSP. A possible explanation for this finding might be that adolescents who desire closeness might try to mask their distress and insecurity by showing others how perfect they are. Impressing others might then be the coping strategy by which they aim to gain love and approval from others and to avoid further disapproval or shame (Flett, Hewitt, Oliver, \& MacDonald, 2002). Indeed, children with an attachment history of conditional approval may have learned that only when one is perfect external approval and love is granted (Hamachek, 1978). Anxious attachment has 
indeed been linked to an attachment history characterized by conditional approval (Park, Crocker, \& Mickelson, 2004). It thus appears that anxiously attached individuals may not only try to attain to the perceived standards and expectations of others (SPP) in an attempt to gain others' love and approval, but may also engage in defensive self-inflation and try to impress others by appearing perfect.

Second, the association between avoidant attachment and SPP on the one hand and PSP on the other hand depended on the attachment figure. As expected, we found that avoidant attachment towards father was related to PSP. Adolescents who were avoidantly attached to their father, appeared to have an excessive need to present themselves as perfect, which might be seen as a deactivating strategy to cope with feelings of vulnerability and distress (Mikulincer, et al., 2003). Since most of the studies on attachment only focused on the role of the mother at the expense of the fathers (Lamb, 2010), it is interesting to see that this association only appeared to be true for the attachment towards fathers. Unexpectedly, avoidant attachment towards mother was related to SPP, suggesting that adolescents who feel threatened by attachment closeness with and dependence of the mother, hold the belief that others have high standards and expectations. Possibly, these adolescents who do not perceive their mother as a valuable option to regulate and manage distress, might compensate for these feelings by trying to attain to the expectations of others in order to gain others' love and approval.

With regard to binge eating, it was found that all insecure attachment representations, except attachment avoidance towards mother, were positively associated with binge eating. The association between insecure attachment and binge eating is in line with previous research (e.g., Ward, et al., 2000) and stresses the importance of the role of the father in attachment and ED symptoms (Bosmans, Goossens, \& Braet, 2009). 
Third, as expected, adolescents who were securely attached experienced less SPP, PSP, and binge eating. This shows that secure attachment might be considered as a protective factor for the development of perfectionism and binge eating. Indeed, adolescents with a secure base have internalized their attachment figure and developed good emotion regulation strategies to cope with stress, making them more resilient (Mikulincer, et al., 2003).

The fourth aim of this study was to examine whether the interpersonal perfectionism components would mediate between attachment representations and binge eating. It was found that SPP and PSP partially mediated the relation between attachment anxiety and secure attachment towards father and mother. Interestingly, PSP appeared to fully explain the relation between attachment avoidance towards the father and binge eating. This finding again stresses the importance of the attachment representation of adolescents to their father for the experience of ED symptoms. Adolescents who did not perceive their father as a safe haven in times of distress, might compensate for these feelings by creating a perfect image of the self towards others. This maladaptive way of coping with feelings and distress might further lead to increases in binge eating symptoms (Spoor, et al., 2007). A second full mediating effect appeared for SPP as mediator in the relation between attachment avoidance towards mother and binge eating. However, it should be noted that the indirect effect of this mediation effect was rather small, which was due to a small effect of attachment avoidance on binge eating.

\subsection{Limitations and directions for future research}

The present study had some limitations. First, the study was cross-sectional in nature, which limits the interpretation of the direction of effects. Although a mediation model was tested in which directions of effects were suggested, we should be careful with the 
interpretation of these findings. Given that recent research showed that there exists not only significant between-person but also within-person variability in attachment (Dunkley, et al., 2012) and perfectionism (Boone, et al., 2012), more dynamic and bidirectional relations may occur. It would be interesting for future research to examine dynamic associations between attachment representations and perfectionism, especially because it has been found that perfectionists have interpersonal difficulties and experience more social disconnection (Chen, et al., 2012). Second, because our findings are based entirely on selfreport measures our obtained associations might be inflated because of shared method variance. Future studies may want to use other methods to measure attachment, such as observational measures or interview-based measures.

\subsection{Implications for treatment}

Our findings pointed to the importance to target both attachment insecurity and maladaptive perfectionism in prevention or treatment programs for adolescents with binge eating symptoms. Although attachment-based family therapy has been found to be successful in promoting adolescent-parent reattachment (Diamond, Diamond, \& Hogue, 2007), this program has not yet been applied to the treatment of eating problems. On the basis of our findings, perfectionism seems to be another important factor to target in treatment. Given that it was hypothesized that adolescents engage in perfectionism as a maladaptive coping strategy and ED patients are found to have poor emotion regulation strategies (Harrison, et al., 2009), treatment may also focus on coping, emotion regulation, and mentalization (Allen, Fonagy, \& Bateman, 2008).

Footnote

${ }^{1}$ Supplementary analyses showed that adolescents who were anxiously attached to only one parent experienced less perfectionism and binge eating compared to those adolescents who 
were anxiously attached to both parents. For avoidant attachment, no such differences were found. 


\section{References}

Abebe, D. S., Lien, L., Torgersen, L., \& von Soest, T. (2012). Binge eating, purging and non-purging compensatory behaviours decrease from adolescence to adulthood: A population-based, longitudinal study. Bmc Public Health, 12.

Allen, J. G., Fonagy, P., \& Bateman, A. (2008). Mentalizing in clinical pratice. Arlington: American Psychiatric Publishing.

Blatt, S. J. (2004). Experiences of Depression: Theoretical, Clinical and Research Perspectives. Washinton, DC: American Psychological Association.

Boone, L., Soenens, B., Thanasis, M., Vansteenkiste, M., Verstuyf, J., \& Braet, C. (2012). Daily fluctuations in perfectionism and their relation to eating disorder symptoms. Journal of Research in Personality, 46, 678-687.

Bosmans, G., Goossens, L., \& Braet, C. (2009). Attachment and weight and shape concerns in inpatient overweight youngsters. Appetite, 53, 454-456.

Bowlby, J. (1982/1969). Attachment and loss: Vol 1. Attachment (2 ed.). New York: Basic Books.

Brenning, K., Soenens, B., Braet, C., \& Bosmans, G. (2012). Attachment and depressive symptoms in middle childhood and early adolescence: Testing the validity of the emotion regulation model of attachment, Personal Relationships, 19, 445-464..

Cassidy, J. (1990). Theoretical and methodological consideration in the study of attachment and the self in young children. In M. T. Greenberg, D. Cicchetti \& E. M. Cummings (Eds.), Attachment in the preschool years: Theory, research and intervention (pp. 87-119). Chicago: Unversity of Chicago Press.

Chen, C., Hewitt, P. L., Flett, G. L., Cassels, T. G., Birch, S., \& Blasberg, J. S. (2012). Insecure attachment, perfectionistic self-presentation, and social disconnection in adolescents. Personality and Individual Differences, 52, 936-941.

ColeDetke, H., \& Kobak, R. (1996). Attachment processes in eating disorder and depression. Journal of Consulting and Clinical Psychology, 64, 282-290. 
Cook, E. T., Greenberg, M. T., \& Kusche, C. A. (1995). People In My Life: Attachment relationships in middle childhood. In Society for Research in Child Development. Indianapolis, IN, March.

Diamond, G. M., Diamond, G. S., \& Hogue, A. (2007). Attachment-based family therapy: Adherence and differentiation. Journal of Marital and Family Therapy, 33, 177-191.

Dunkley, D. M., Berg, J.-L., \& Zuroff, D. C. (2012). The Role of Perfectionism in Daily Self-Esteem, Attachment, and Negative Affect. Journal of Personality, 80, 633-663.

Fairburn, C. G., Cooper, Z., \& Shafran, R. (2003). Cognitive behaviour therapy for eating disorders: a "transdiagnostic" theory and treatment. Behaviour Research and Therapy, 41, 509-528.

Flett, G. L., Hewitt, P. L., Oliver, J. M., \& MacDonald, S. (2002). Perfectionism in children and their parents: A developmental analysis. In G. L. F. P. L. Hewitt (Ed.), Perfectionism: Theory, research, and treatment (pp. 89-132). Washington, DC American Psychological Association.

Fraley, R. C., Waller, N. G., \& Brennan, K. A. (2000). An item response theory analysis of self-report measures of adult attachment. Journal of Personality and Social Psychology, 78, 350-365.

Garner, D. M. (1991). Eating Disorder Inventory-2 professional manual. Odessa, FL: Psychological Assessment Resources.

Hamachek, D. E. (1978). Psychodynamics of normal and neurotic perfectionism Psychology, 15, 2733.

Harrison, A., Sullivan, S., Tchanturia, K., \& Treasure, J. (2009). Emotion Recognition and Regulation in Anorexia Nervosa. Clinical Psychology \& Psychotherapy, 16, 348-356.

Hewitt, P. L., \& Flett, G. L. (1991). Perfectionism in the self and social context - conceptualization, assessment, and association with psychopathology. Journal of Personality and Social Psychology, 60, 456-470.

Hewitt, P. L., Flett, G. L., \& Ediger, E. (1995). Perfectionism traits and perfectionistic self-presentation in eating disorder attitudes, characteristics, and symptoms. International Journal of Eating Disorders, 18, 317-326. 
Hewitt, P. L., Flett, G. L., Sherry, S. B., Habke, M., Parkin, M., Lam, R. W., McMurtry, B., Ediger, E., Fairlie, P., \& Stein, M. B. (2003). The interpersonal expression of perfection: Perfectionistic self-presentation and psychological distress. Journal of Personality and Social Psychology, 84, $1303-1325$.

Kenny, D. A., Kashy, D. A., \& Bolger, N. (1998). Data analysis in social psychology. In D. Gilbert, S. Fiske \& G. Lindzey (Eds.), The handbook of social psychology. Boston, MA: McGraw-Hill. Lamb, M. (2010). The role of the father in child development (5 ed.). New York: Guilford.

Mikulincer, M., \& Shaver, P. R. (2007). Attachment in adulthood. New York London: The guilford press.

Mikulincer, M., Shaver, P. R., \& Pereg, D. (2003). Attachment theory and affect regulation: The dynamics, development, and cognitive consequences of attachment-related strategies. Motivation and Emotion, 27, 77-102.

Murray, C., \& Greenberg, M. T. (2006). Examining the Importance of Social Relationships and Social Contexts in the Lives of Children With High-Incidence Disabilities. The Journal of Special Eductation, 39, 220-233.

Pace, U., Cacioppo, M., \& Schimmenti, A. (2012). The Moderating Role of Father's Care on the Onset of Binge Eating Symptoms Among Female Late Adolescents with Insecure Attachment. Child Psychiatry \& Human Development, 43, 282-292.

Park, L. E., Crocker, J., \& Mickelson, K. D. (2004). Attachment styles and contingencies of self-worth. Personality and Social Psychology Bulletin, 30, 1243-1254.

Preacher, K. J., \& Hayes, A. F. (2004). SPSS and SAS procedures for estimating indirect effects in simple mediation models. Behavior Research Methods Instruments \& Computers, $36,717-731$.

Rice, K. G., \& Mirzadeh, S. A. (2000). Perfectionism, attachment, and adjustment. Journal of Counseling Psychology, 47, 238-250. 
Shaver, P. R., \& Mikulincer, M. (2002). Attachment-related psychodynamics. Attachment \& Human Development, 4, 133-161.

Sobel, M. E. (1982). Asymptotic intervals for indirect effects in structural equations models. In S. Leinhart (Ed.), Sociological methodology (pp. 290-312). San Francisco: Jossey-Bass.

Spoor, S. T. P., Bekker, M. H. J., Van Strien, T., \& van Heck, G. L. (2007). Relations between negative affect, coping, and emotional eating. Appetite, 48, 368-376.

Thompson, R., \& Zuroff, D. C. (1999). Development of self-criticism in adolescent girls: Roles of maternal dissatisfaction, maternal coldness, and insecure attachment. Journal of Youth and Adolescence, 28, 197-210.

Ward, A., Ramsay, R., \& Treasure, J. (2000). Attachment research in eating disorders. British Journal of Medical Psychology, 73, 35-51.

Wei, M. F., Heppner, P. P., Russell, D. W., \& Young, S. K. (2006). Maladaptive perfectionism and ineffective coping as mediators between attachment and future depression: A prospective analysis. Journal of Counseling Psychology, 53, 67-79.

Zachrisson, H. D., \& Skarderud, F. (2010). Feelings of Insecurity: Review of Attachment and Eating Disorders. European Eating Disorders Review, 18, 97-106. 
Reliability, Means, Standard Deviations, and Correlations of the Study Variables.

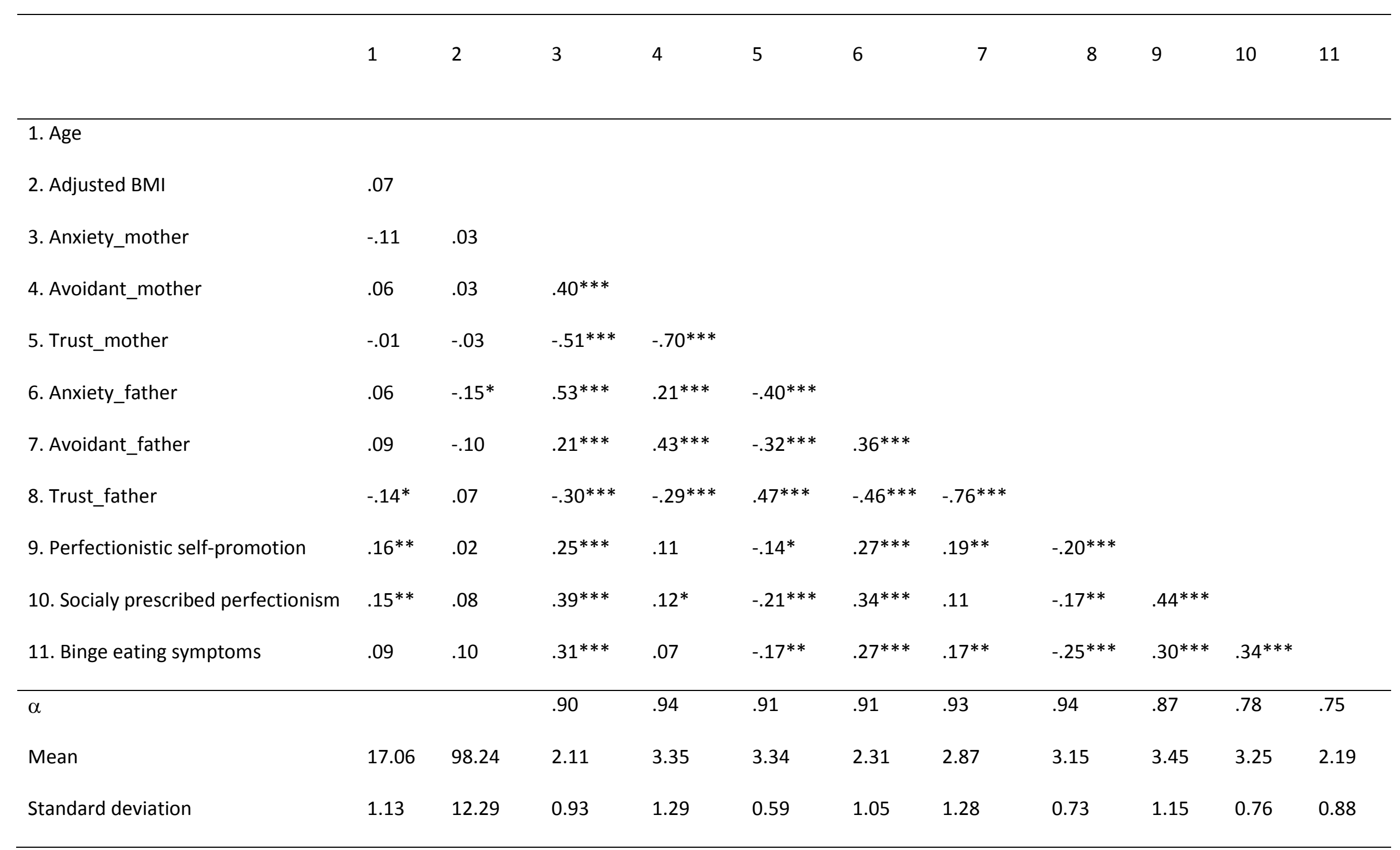

Note. Adjusted Body Mass Index (BMI) = [(actual BMI / percentile 50 of BMI for age and gender) x 100].

$* p<.05, * * p<.01 * * * p<.001$ 
Table 2

Mediation analyses with standardized betas for socially prescribed perfectionism (SPP) and perfectionistic self-promotion (PSP) as mediating variables between attachment styles and binge eating, controlling for the effects of gender, age, adjusted BMI, and family status.

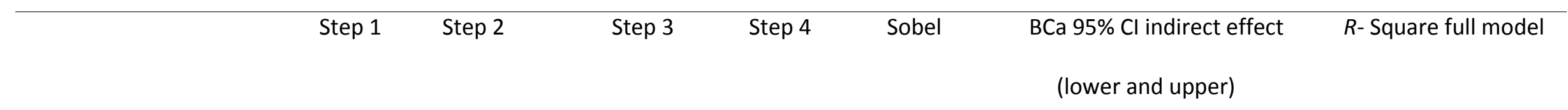

Mediator SPP

\begin{tabular}{|c|c|c|c|c|c|c|c|c|}
\hline Anxiety_mother & $.33 * * *$ & $.36 * * *$ & $.23 * * *$ & $.24 * * *$ & $4.55^{* * *}$ & .0390 & 1381 & $.21^{* * *}$ \\
\hline Avoidance_mother & $.13^{*}$ & $.13 *$ & $.31 * * *$ & .09 & $2.10^{*}$ & .0028 & .0688 & $.17^{* * *}$ \\
\hline Trust_mother & $-.20 * * *$ & $-.21 * * *$ & $.30 * * *$ & $-.14^{*}$ & $-3.12 * * *$ & -.1752 & -.0376 & $.18^{* * *}$ \\
\hline Anxiety_father & $.29 * * *$ & $.34 * * *$ & $.26 * * *$ & $.21 * * *$ & $4.28 * * *$ & .0340 & .1272 & $.20 * * *$ \\
\hline Avoidance_father & $.15^{*}$ & .10 & $.31 * * *$ & $.12^{*}$ & $1.62+$ & -.0055 & .0559 & $.18^{* * *}$ \\
\hline Trust_father & $-.23 * * *$ & $-.15^{*}$ & $.30 * * *$ & $-.19 * *$ & $-2.34^{*}$ & -.1178 & -.0146 & $.19 * * *$ \\
\hline \multicolumn{9}{|l|}{ Mediator PSP } \\
\hline Anxiety_mother & $.32 * * *$ & $.24 * * *$ & $.23 * * *$ & $.27 * * *$ & $3.39 * * *$ & .0212 & .0972 & $.21 * * *$ \\
\hline Avoidance_mother & $.13^{*}$ & .11 & $.28 * * *$ & .10 & $1.78^{+}$ & -.0003 & .0571 & $.17 * * *$ \\
\hline Trust_mother & $-.20 * *$ & $-.13^{*}$ & $.27^{* * *}$ & $-.16 * *$ & $-2.11^{*}$ & -.1214 & -.0098 & $.17^{* * *}$ \\
\hline Anxiety_father & $.29 * * *$ & $.28 * * *$ & $.23 * * *$ & $.23 * * *$ & $3.62^{* * *}$ & .0226 & .1006 & $.19 * * *$ \\
\hline Avoidance_father & $15^{* *}$ & $.20 * *$ & $.28 * * *$ & .10 & $2.92 * * *$ & .0130 & .0774 & $.15^{* * *}$ \\
\hline Trust_father & $-.23 * * *$ & $-.20 * *$ & $.26 * * *$ & $-.18^{* *}$ & $-2.89 * * *$ & -.1275 & -.0211 & $.17^{* * *}$ \\
\hline
\end{tabular}

Note. Step 1= path from independent (attachment) to dependent variable (binge eating). Step 2 = path from independent to mediating variable (SPP or PSP).

Step 3 = path from mediating to dependent variable (controlling for the independent variable). Step 4 = path from independent to dependent variable (controlling for the mediator). $\mathrm{BCa}=$ bias-corrected and accelerated (BCa); 1000 bootstrap samples. ${ }^{\dagger} \mathrm{p}<.10,{ }^{*} p<.05,{ }^{* *} p<.01,{ }^{* * *} p<.001$. 